\title{
Emerging norovirus GII.4 2008 variant detected in hospitalised paediatric patients in South Africa
}

\author{
Janet Mans $^{\mathrm{a}, *}$, J. Corrie de Villiers ${ }^{\mathrm{b}}$, Nicolette M. du Plessis ${ }^{\mathrm{c}}$, Theunis Avenant ${ }^{\mathrm{c}}$, Maureen B. Taylor ${ }^{\mathrm{a}, \mathrm{b}}$ \\ a Department of Medical Virology, Faculty of Health Sciences, University of Pretoria, P.O. Box 2034, Pretoria 0001, Gauteng, South Africa \\ ${ }^{\mathrm{b}}$ National Health Laboratory Service, Tshwane Academic Division, Pretoria, South Africa \\ ${ }^{\text {c }}$ Paediatric Infectious Diseases Unit, Faculty of Health Sciences, University of Pretoria, South Africa
}

\section{A R T I C L E I N F O}

\section{Article history:}

Received 18 February 2010

Received in revised form 4 August 2010

Accepted 23 August 2010

\section{Keywords:}

Norovirus gastroenteritis

Paediatric

GII.4 2008 variant

South Africa

\begin{abstract}
A B S T R A C T
Background: Noroviruses (NoVs) are important enteric pathogens that cause gastroenteritis worldwide. The first documented NoV outbreaks in South Africa (SA) were described in 1993. The current NoV prevalence and circulating genotypes are unknown. SA lacks NoV outbreak reporting systems and therefore the number and impact of NoV infections is underestimated.

Objectives: This study aimed to determine the prevalence and genetic diversity of NoV infections in hospitalised paediatric patients with gastroenteritis in SA during 2008.

Study design: Stool specimens referred for virological analysis from hospitalised children $\leq 13$ years, with gastroenteritis, were screened for rotavirus, human adenovirus and human astrovirus by enzyme immunoassay and for NoV genogroup I (GI), II (GII) and sapovirus by real-time RT-PCR. NoV strains were genotyped, and variants identified, based on sequence and phylogenetic analyses of the $5^{\prime}$ end or the full length of the capsid gene, respectively.

Results: Rotavirus was the most prevalent virus detected in $24.2 \%$ (61/252) of specimens, followed by NoV in $14.3 \%$ (35/245) and adenovirus, astrovirus and sapovirus in $9.6 \%, 6.7 \%$ and $4 \%$ of specimens, respectively. NoVs were only detected in children $\leq 2$ years. The GII NoVs $(89 \%)$ predominated and eight types were identified with GII.4 (43\%) detected most frequently. The emerging 2008 GII.4 variant represented $80 \%$ of the GII.4 strains.

Conclusions: A diverse range of NoV genotypes were identified in hospitalised children with gastroenteritis. The 2008 GII.4 variant was the most frequently detected strain in the study. This is the first report of NoV GII.4 viruses in SA.
\end{abstract}

(C) 2010 Elsevier B.V. All rights reserved.

\section{Background}

Viral gastroenteritis can cause life threatening disease in infants and young children, especially in the developing world. ${ }^{1}$ Viruses implicated most frequently are group A rotaviruses (RV), human caliciviruses (HuCVs), enteric adenoviruses (AdVs) types 40/41 and human astroviruses (HAstVs). ${ }^{2}$ Noroviruses (NoVs), classified in the Caliciviridae family, are small, non-enveloped RNA viruses (single-stranded, positive-sense genome, $\sim 7.7 \mathrm{~kb}$ ). Based on RNA polymerase or capsid gene sequence analysis, NoVs are divided into five genogroups. The genogroups are further divided into genotypes, currently there are eight types in genogroup I (GI), at least

Abbreviations: AdV, adenovirus; EIA, enzyme immunoassay; G, genogroup; HAstV, human astrovirus; HIV, human immunodeficiency virus; NoV, norovirus; RTPCR, reverse transcriptase-polymerase chain reaction; RV, rotavirus; SaV, sapovirus; SA, South Africa.

* Corresponding author. Tel.: +27 12319 2534; fax: +27 123255550.

E-mail addresses: janet.mans@tuks.co.za, janetmans0001@yahoo.com (J. Mans).
17 in GII and two in GIII. ${ }^{3}$ GI, GII and GIV infect humans ${ }^{4}$ with GII.4 strains currently the leading cause of NoV outbreaks worldwide. ${ }^{5}$ GII.4 variants emerge almost annually, spread rapidly and some become dominant for several seasons. ${ }^{6}$ NoVs infect persons of all ages and cause gastroenteritis $10-51 \mathrm{~h}$ after infection. Symptoms may include fever, nausea, abdominal cramps, vomiting and watery diarrhoea. $^{4}$

Initially described after a gastroenteritis outbreak at a school in Norwalk, Ohio in $1968,{ }^{7}$ NoVs are now known to cause large gastroenteritis epidemics worldwide. ${ }^{8-10}$ Outbreaks often occur due to contaminated food or water and are difficult to control because of the high environmental stability, low infectious dose and high rate of secondary spread characteristic of NoVs. ${ }^{11}$ Over the last 3 years a number of studies have investigated the prevalence of NoV infection in hospitalised children. ${ }^{5}$ A wide range of prevalences $(6-48 \%)$ were reported with a median of $14 \%, 5$ and in some studies NoV-associated gastroenteritis was almost as common as RV infections ${ }^{12-14}$ indicating that NoVs may be clinically more relevant than previously thought. 
Table 1

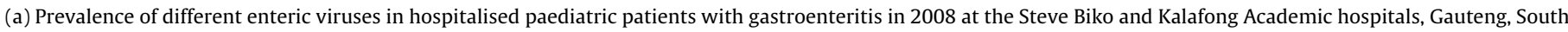
Africa, (b) Norovirus (NoV) genogroup distribution, and (c) Viral co-infections in NoV positive specimens.

\begin{tabular}{|c|c|c|}
\hline (a) Virus & Positive specimens/Total number tested & Prevalence (\%) \\
\hline Group A RV & $61 / 252$ & 24.21 \\
\hline $\mathrm{NoV}$ GI + GII & $35 / 245$ & 14.29 \\
\hline AdV $40 / 41^{\mathrm{a}}$ & $23 / 240$ & 9.58 \\
\hline HAstV ${ }^{\mathrm{a}}$ & $16 / 239$ & 6.69 \\
\hline $\mathrm{SaV}^{\mathrm{b}}$ & $10 / 245$ & 4.08 \\
\hline
\end{tabular}

\begin{tabular}{|c|c|c|}
\hline (b) NoV genogroup & NoV positive samples/Total & $(\%)$ \\
\hline Genogroup I & $3 / 245$ & 1.22 \\
\hline Genogroup II & $31 / 245$ & 12.65 \\
\hline $\mathrm{GI}+\mathrm{GII}$ & $1 / 245$ & 0.41 \\
\hline Total & $35 / 245$ & 14.29 \\
\hline
\end{tabular}

(c) Distribution of mixed and single-virus infections in NoV positive specimens

\begin{tabular}{llc}
\hline Positive for NoV & $35^{\mathrm{c}}$ & 100 \\
NoV only detected & 27 & 77.1 \\
Two viruses detected & 2 & 5.7 \\
NoV, RV & 1 & 2.9 \\
NoV, AdV & 1 & 2.9 \\
NoV, SaV & & 8.5 \\
Three viruses detected & 3 & 2.9 \\
NoV, RV, AdV & 1 & \\
NoV, RV, HAstV & & \\
\hline
\end{tabular}

\footnotetext{
a Tested by EIA.

b Tested by real-time RT-PCR. Adenovirus (AdV), human astrovirus (HAstV), norovirus genogroup I or II (NoV GI, GII), rotavirus (RV), sapovirus (SaV),

c $12 / 35$ NoV positive specimens were screened for bacteria and parasites and all were negative.
}

NoV-associated gastroenteritis outbreaks were first reported in South Africa (SA) in 1993. ${ }^{15}$ The Norwalk (GI.1) and Hawaii (GII.1) strains were identified as the causative agents in the respective outbreaks. In 1995, Mexico-like viruses (GII.3) were identified in paediatric stool specimens from sporadic gastroenteritis cases. ${ }^{16}$ In 1997, the prevalence of HuCV infection in SA was estimated to be $3.3 \%$, with NoVs representing $89 \%$ and sapoviruses ( $\mathrm{SaVs}$ ) $11 \%{ }^{17}$ NoV GI and GII viruses were identified, but the GII strains (Mexicolike) predominated. A seroepidemiological study in the Pretoria area of SA indicated that $57 \%$ of children were exposed to NoV by $1-2$ years of age and that $62 \%$ of the population was seropositive by the age of $40 .^{18}$ A later study reported NoV antibody prevalence levels of $94-96 \%$ in both urban and rural South African populations. ${ }^{19}$ It is evident that NoV infections in SA occur early in life and affect all groups of the population. In the past 10 years no data on NoV prevalence or circulating genotypes have been reported for SA. There is also no mandatory gastroenteritis outbreak reporting system in the health care/old-age home setting. Therefore sporadic cases and outbreaks of NoV may be underreported and the prevalence of these infections underestimated.

\section{Objectives}

The aim of this study was to determine the prevalence and genetic diversity of NoV infections in South African hospitalised paediatric patients with gastroenteritis and to compare the circulating genotypes with NoV strains that are currently found worldwide.

\section{Study design}

\subsection{Sample collection and processing}

In a retrospective study, stool specimens, from hospitalised patients ( $\leq 13$ years old) with gastroenteritis symptoms, submitted from January to December 2008 to a routine diagnostic laboratory for gastroenteritis virus testing were subsequently screened for NoV and SaV. Specimens were received from the Steve Biko and Kalafong Academic Hospitals, Gauteng, SA and stored at $4{ }^{\circ} \mathrm{C}$ until processing. Stool specimens were routinely tested by enzyme immunoassay (EIA) for RV (Premier Rotaclone, Meridian Biosciences Inc., Cincinatti, OH) and/or AdV 40/41 (Premier Adenoclone 40/41, Meridian Biosciences Inc.) and/or HAstV (Amplified IDEIA Astrovirus, Oxoid, Ely, UK) according to the manufacturer's instructions. Screening for NoV and SaV was done by real-time reverse transcriptase-polymerase chain reaction (RT-PCR). Stool suspensions (10-20\%) were prepared in water and nucleic acids were extracted from $200 \mu \mathrm{l}$ suspension with a total nucleic acid isolation kit (Roche Diagnostics, Mannheim, Germany) in a MagNA Pure LC robotic instrument (Roche Diagnostics). Total nucleic acid was eluted in $50 \mu$ l elution buffer, aliquoted and stored at $-70^{\circ} \mathrm{C}$ before use.

\subsection{Statistical analyses}

Descriptive statistics were used to summarise demographic data. Human immunodeficiency virus (HIV) positive and negative groups were compared in terms of acute or chronic infection using the Mantel-Haenszel Chi-square test (http://www.openepi.com/TwobyTwo/TwobyTwo.htm).

\subsection{Detection and genotyping of NoVs}

Published primer sets, Taqman probes and the QuantiTect Probe RT-PCR kit (Qiagen Inc., Valencia, CA) were used to detect NoV $\mathrm{GI}^{20,21}$ or $\mathrm{GII}^{22,23}$ and $\mathrm{SaV}{ }^{24}$ For genotyping the $5^{\prime}$ end of the NoV capsid gene (Region $C$ ) was amplified and sequenced. Random primed cDNA was prepared from $10 \mu$ l total RNA using the Transcriptor First Strand cDNA Synthesis Kit (Roche Diagnostics). Conventional PCR was performed with primers G1SKF, G1SKR, G2SKF and G2SKR ${ }^{25}$ and HotStarTaq (Qiagen Inc.) according to the manufacturer's recommendations. M13(-21) and M13REV primer sequences $^{26}$ were added at the $5^{\prime}$ end of primers to facilitate sequencing using the ABI PRISM BigDye ${ }^{\circledR}$ Terminator v3.1 Cycle Sequencing Kit on an ABI 3130 automated analyser (Applied Biosystems, Foster City, CA). 
Table 2

Distribution of (a) norovirus (NoV) and rotavirus (RV) infections among different age groups, (b) NoV and RV infections by month during 2008.

\begin{tabular}{|c|c|c|}
\hline \multicolumn{3}{|c|}{ (a) Age distribution of NoV and RV infections } \\
\hline Age groups & NoV positive/Total & RV positive/Total \\
\hline 0-6 months & $15 / 103$ & $25 / 105$ \\
\hline 7-12 months & $11 / 54$ & $28 / 87$ \\
\hline 13-18 months & $5 / 25$ & $2 / 4$ \\
\hline 19-24 months & $4 / 26$ & $3 / 19$ \\
\hline$>2-4$ years & $0 / 14$ & $0 / 8$ \\
\hline$>4-6$ years & $0 / 10$ & $0 / 8$ \\
\hline$>6-8$ years & $0 / 9$ & $2 / 10$ \\
\hline$>8-13$ years & $0 / 4$ & $0 / 5$ \\
\hline Unknown & - & $1 / 6$ \\
\hline Total & $35 / 245$ & $61 / 252$ \\
\hline \multicolumn{3}{|c|}{ (b) Seasonal distribution of NoV and RV infections } \\
\hline Month & NoV positive/Total & RV positive/Total \\
\hline January & $2 / 19$ & $5 / 20$ \\
\hline February & $4 / 27$ & $5 / 26$ \\
\hline March & $2 / 25$ & $4 / 26$ \\
\hline April & $1 / 18$ & $10 / 21$ \\
\hline May & $4 / 29$ & $10 / 31$ \\
\hline June & $1 / 17$ & $6 / 17$ \\
\hline July & $2 / 22$ & $8 / 22$ \\
\hline August & $1 / 16$ & $7 / 16$ \\
\hline September & $1 / 7$ & $0 / 6$ \\
\hline October & $3 / 14$ & $2 / 15$ \\
\hline November & $6 / 19$ & $1 / 18$ \\
\hline December & $8 / 32$ & $3 / 34$ \\
\hline Total & $35 / 245$ & $61 / 252$ \\
\hline
\end{tabular}

Nucleotide sequences were analysed using Sequencher ${ }^{\mathrm{TM}} 4.9$ (Gene Codes Corporation, Ann Arbor, MI), BioEdit Sequence Alignment Editor (V.7.0.9.0 $)^{27}$ and BLAST-N. ${ }^{28}$ Sequences were aligned with reference sequences from genogroup I, II and IV using MAFFT Version 6 (https://align.bmr.kyushu-u.ac.jp/mafft/online/server/). After manual adjustment of the alignment, phylogenetic analysis was performed with MEGA4 using neighbour-joining methods. ${ }^{29}$ GII.4 variants were identified by phylogenetic analysis of full length capsid sequences using GII.4 variant reference strains isolated from 1996 to 2008. Full capsid sequences were obtained by amplification of randomly primed cDNA with primers GR-JS1, GR19B, GR20A, GR21, GR22, GR23newR (TTATACAGCACGTCTACGCC), GR24A and GR25 $5^{30}$ and sequencing of four overlapping fragments that span the capsid gene. Only nucleotide sequences with less than $98 \%$ identity to NoV sequences in GenBank were submitted to the database. GenBank accession numbers are shown in Fig. 2.

\section{Results}

4.1. Prevalence of NoV and other gastroenteritis viruses in diarrhoeal specimens from hospitalised children

The median age of the study population was 8 months (range 1 day to 13 years) and the female to male ratio was $1: 1.45$. Of the stool specimens submitted for testing, 252 were tested for RV, 245 for NoV and SaV, 240 for AdV and 239 for HAstV. RV was identified in $24.2 \%(61 / 252)$ of specimens and was the most prevalent virus detected (Table 1a). NoVs, including GI and GII were detected in $14.3 \%$ (35/245) of the specimens whereas AdV 40/41, HAstV and SaV were detected in $9.6 \%, 6.7 \%$ and $4 \%$ of the specimens, respectively. NoVs were only detected in children up to 2 years old, as was $96.6 \%$ of RV (Table $2 \mathrm{a}$ ), $95.7 \%$ of AdV $40 / 41$ and $93.8 \%$ of HAstV (data not shown). NoVs were detected throughout 2008 with an increase in the positive specimens in November and December (Table 2b). RV infections peaked between April and August of 2008 (Table 2b). NoV
GI (3/245) and GII (31/245) as well as one mixed GI + GII infection was detected (Table $1 \mathrm{~b}$ ).

Viral co-infections were identified in $23 \%$ of the NoV positive specimens (Table 1c). Co-infections with RV, AdV or SaV alone or a combination of RV/AdV and RV/HAstV were identified. Twelve of the $35 \mathrm{NoV}$ positive specimens had been screened for bacteria and parasites but the results were negative. Approximately $80 \%$ of the NoV infections were community acquired infections whereas $20 \%$ of the patients possibly represented nosocomial infections. Community acquired infections predominated in children up to 18 months of age (Fig. 1a).
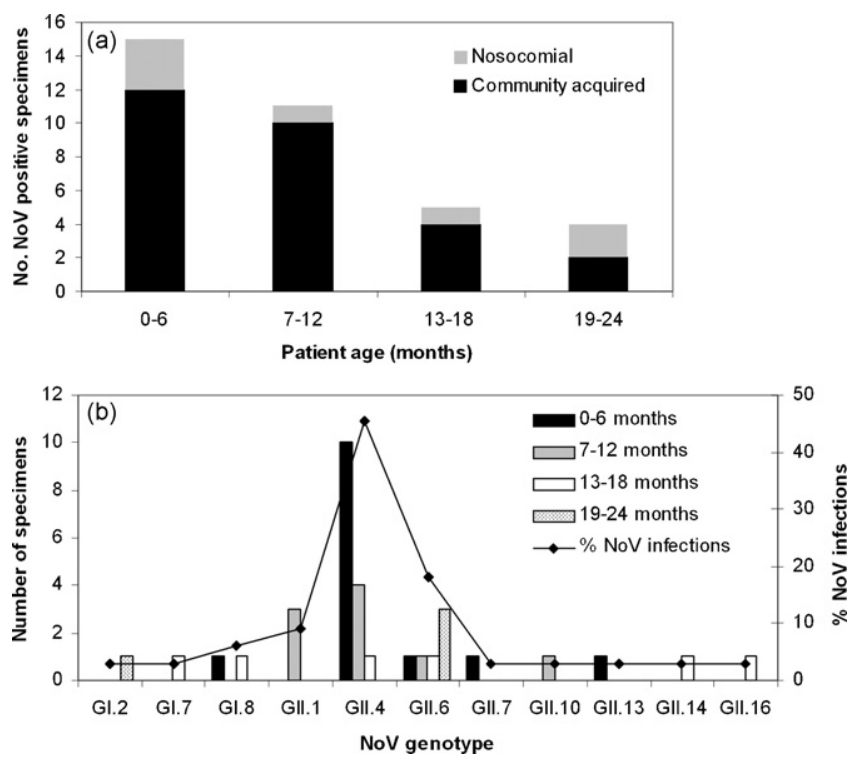

Fig. 1. (a) Distribution of community acquired and nosocomial norovirus (NoV) infections in hospitalised children of different ages. (b) NoV genotype distribution within four age groups (0-6 months, 7-12 months, 13-18 months and 19-24 months) of hospitalised paediatric patients. 
(a)

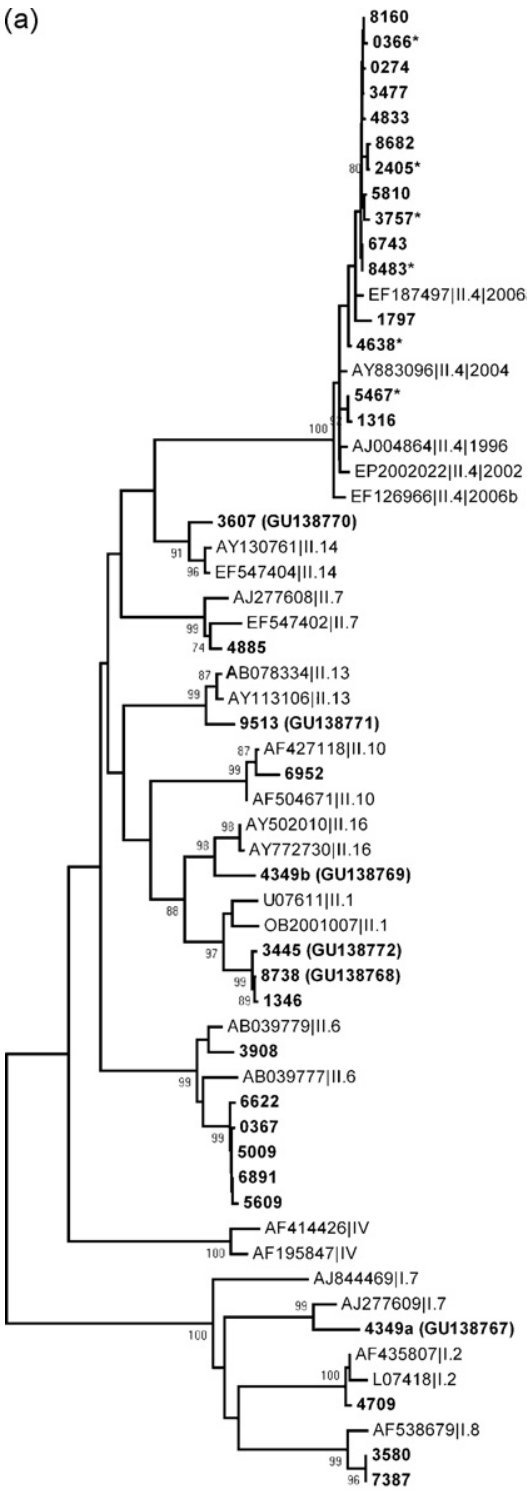

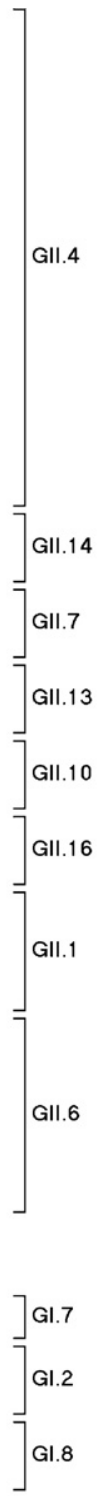

(b)

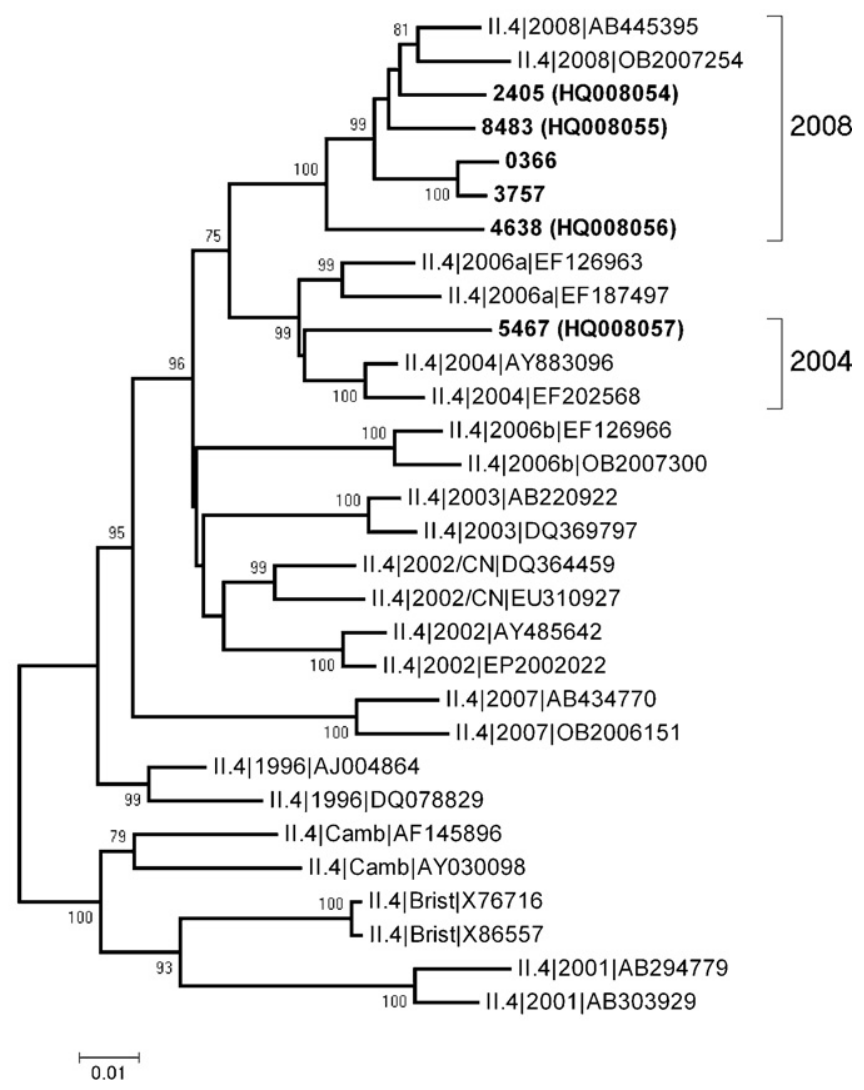

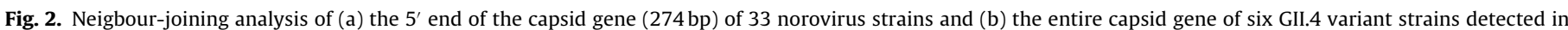

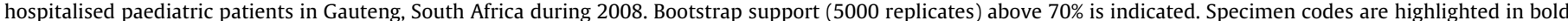

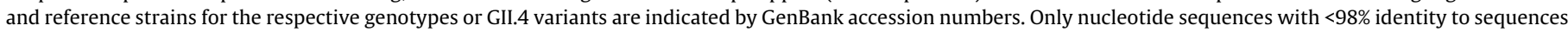
in GenBank were submitted to the database. *Indicates representative GII.4 variant strains selected for full capsid sequencing.

\subsection{NoV genotypes identified in diarrhoeal specimens from hospitalised children}

Phylogenetic analysis of the $5^{\prime}$ end of the NoV capsid gene revealed a variety of NoV genotypes circulating in the hospitalised paediatric population. NoV could not be amplified by conventional RT-PCR from three specimens, originally detected by GII-specific real-time RT-PCR using Taqman probes $(\mathrm{Cp}>36)$, and these remain untyped. Three different GI strains, GI.2 (25\%), GI.7 (25\%) and GI.8 (50\%), were characterised (Fig. 2a and Table 3). The GII NoVs (89\%) predominated and eight GII types were identified (Fig. 2a and Table 3) with GII.4 (43\%), GII.6 (17\%) and GII.1 (9\%) detected most frequently. Several other GII types were found in single specimens. Phylogenetic analyses of region C of the GII.4 strains indicated clustering of 73\% of the strains with the GII.4 2008 variant, however without significant bootstrap support (data not shown). Therefore the full capsid sequences of six representative GII.4 strains were determined. Neighbour-joining analysis of these sequences with
GII.4 variant reference sequences confirmed that the strains cluster with the 2008 variant (Fig. 2b and Table 3). In addition two 2004 variants were identified. The full capsid sequence of isolate 1797 , which groups separately from the other GII.4 strains (Fig. 2a), could not be determined and therefore no variant could be assigned.

In Fig. 1b the distribution of NoV genotypes within the age groups $0-6,7-12,13-18$ and $19-24$ months is shown. GII.4 strains were detected in $66 \%$ of the patients in the 0-6 month group, whereas both GII.4 (44\%) and GII.1 (33\%) strains were predominant in the 7-12 month age group. The other genotypes were distributed randomly.

Of the $35 \mathrm{NoV}$ positive specimens, 15 were collected from HIV positive patients, 14 from HIV negative patients and six from patients of unknown HIV status. No correlation was observed between NoV genotype and HIV status (Table 3 ). Diarrhoeal cases were classified as acute (60\%) or chronic (37\%). The median duration of hospitalisation for the acute cases was 2 days (range 1-155), and 24 days (range 4-117) for patients with chronic infections. 
Table 3

Norovirus genotypes and GII.4 variants detected in hospitalised paediatric patients in Gauteng, South Africa, during 2008.

\begin{tabular}{|c|c|c|c|c|c|c|}
\hline Specimen code & $\begin{array}{l}\text { Patient age } \\
\text { (months) }\end{array}$ & HIV status & $\begin{array}{l}\text { Community } \\
\text { acquired/nosocomial }\end{array}$ & $\begin{array}{l}\text { Acute/Chronic } \\
\text { diarrhoea (duration } \\
\text { of hospitalisation } \\
\text { in days) }\end{array}$ & $\begin{array}{l}\text { Genotype based on } \\
5 \text { ' end of capsid } \\
\text { gene }\end{array}$ & $\begin{array}{l}\text { GenBank accession } \\
\text { number }^{\mathrm{a}}\end{array}$ \\
\hline & 0-6 months & & & & & \\
\hline $0366^{\mathrm{b}}$ & 2 & Neg & CA & Acute (2) & GII.4 2008 & GQ845367.1 \\
\hline 8733 & 2 & Neg & CA & Acute (1) & Not typed & \\
\hline 6622 & 3.5 & Pos & $\mathrm{CA}$ & Acute (11) & GII.6 & EU007781.1 \\
\hline 1797 & 4 & Neg & CA & Chronic (23) & GII.4 & AB496912.1 \\
\hline $3757^{b}$ & 4 & Pos & NS & Acute (26) & GII.4 2008 & GQ845367.1 \\
\hline 7387 & 4 & ND & CA & Chronic (10) & GI.8 & FJ788383.1 \\
\hline 8160 & 4 & ND & $\mathrm{CA}$ & Acute (2) & GII.4 2008 & GQ845367.1 \\
\hline $8483^{b}$ & 4.5 & Neg & NS & Chronic (117) & GII.4 2008 & HQ008055 \\
\hline 4885 & 5 & Pos & NS & Chronic (25) & GII.7 & AB453773.1 \\
\hline $5467^{b}$ & 5.5 & ND & CA & Acute (1) & GII.4 2004 & HQ008057 \\
\hline 3477 & 5.5 & Pos & $\mathrm{CA}$ & Acute (7) & GII.4 2008 & GQ845367.1 \\
\hline 0274 & 5.75 & ND & CA & Acute (3) & GII.4 2008 & GQ845367.1 \\
\hline 9513 & 6 & Neg & CA & Acute (10) & GII.13 & GU138771 \\
\hline 1316 & 6 & Pos & CA & Chronic (24) & GII.4 2004 & EU876886.1 \\
\hline \multirow[t]{2}{*}{5810} & 6 & ND & CA & Acute (1) & GII.4 2008 & GQ845367.1 \\
\hline & 7-12 months & & & & & \\
\hline $2405^{b}$ & 7.5 & Pos & CA & Chronic (13) & GII.4 2008 & HQ008054 \\
\hline 6743 & 7.75 & Pos & NS & Acute (93) & GII.4 2008 & GQ845367.1 \\
\hline 6952 & 8 & Pos & CA & Chronic (110) & GII.10 & GU724780 \\
\hline 8738 & 8 & Neg & $\mathrm{CA}$ & Chronic (7) & GII.1 & GU138768 \\
\hline 1346 & 8.5 & Pos & CA & Chronic (66) & GII.1 & GU138768 \\
\hline 5609 & 9 & Pos & $\mathrm{CA}$ & Acute (13) & GII.6 & EU007781.1 \\
\hline 2055 & 9.25 & Neg & $\mathrm{CA}$ & ND (16) & Not typed & \\
\hline 9899 & 11 & Neg & $\mathrm{CA}$ & Acute (2) & Not typed & \\
\hline 4833 & 11 & Neg & CA & Acute (1) & GII.4 2008 & GQ845367.1 \\
\hline 3445 & 12 & Neg & $\mathrm{CA}$ & Acute (2) & GII.1 & GU138772 \\
\hline \multirow[t]{2}{*}{8682} & 12 & Pos & CA & Acute (11) & GII.4 2008 & AB491291.1 \\
\hline & 13-18 months & & & & & \\
\hline $4638^{b}$ & 13.25 & Pos & CA & Chronic (37) & GII.4 2008 & HQ008056 \\
\hline 4349 & 14.5 & Pos & NS & Acute (155) & GI.7/GII.16 & GU138767/GU138769 \\
\hline 0367 & 15 & Pos & CA & Chronic (10) & GII.6 & EU007781.1 \\
\hline 3607 & 17 & ND & $\mathrm{CA}$ & Chronic (4) & GII.14 & GU138770 \\
\hline \multirow[t]{2}{*}{3580} & 17.5 & Neg & CA & Acute (2) & GI.8 & FJ788383.1 \\
\hline & 19-24 months & & & & & \\
\hline 3908 & 19 & Pos & NS & Chronic (46) & GII.6 & EU007768.1 \\
\hline 4709 & 20 & Neg & $\mathrm{CA}$ & Acute (1) & GI.2 & FJ383881.1 \\
\hline 5009 & 20 & Neg & $\mathrm{CA}$ & Acute (1) & GII.6 & EU007781.1 \\
\hline 6891 & 24 & Neg & NS & Acute (114) & GII.6 & EU007781.1 \\
\hline
\end{tabular}

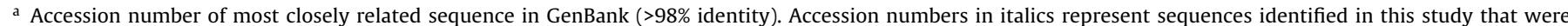

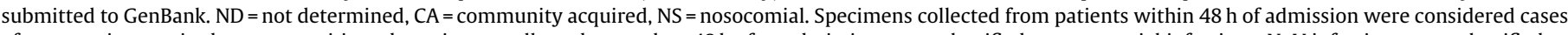

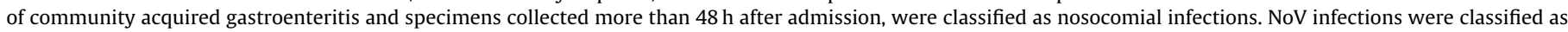
acute ( $\leq 7$ days) or chronic ( $\geq 7$ days) based on the duration of symptoms.

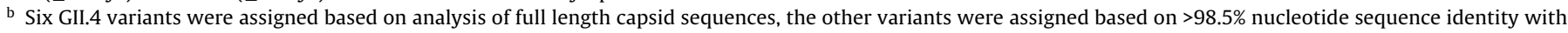
$0366,3757,8483,5467,2405$ and 4638 in the $5^{\prime}$ end region.

In the HIV positive group chronic infections were observed frequently (8/15), whereas HIV negative patients were often acutely infected (10/14) (Table 3). However, this trend was not statistically significant.

\section{Discussion}

Between January and December 2008, NoVs were detected in $35 / 245$ (14.3\%) stool specimens from hospitalised children with gastroenteritis in the Pretoria region, SA. After RV, NoV was the most prevalent virus detected followed by AdV 40/41, HAstV and $\mathrm{SaV}$. These results are consistent with recent studies that describe $\mathrm{RV}$ as the most prevalent and NoV as the second most important viral agent causing gastroenteritis in children (RV 16.6-71.4\%; NoV $12-17.3 \%) .{ }^{31-35}$ The NoV and SaV prevalence determined in the current study is higher than previously estimated in the same region, ${ }^{17}$ which could be attributed to the more sensitive realtime RT-PCR detection method applied. NoVs were detected only in children up to 2 years old (median age 8 months), which is in agreement with studies in Brazil and Nicaragua where more frequent NoV infections in children $\leq 2$ years old were reported. ${ }^{36,37}$ This could indicate that short term immunity is generated to NoV, since NoV infections in older children and adults are common. ${ }^{38}$ Alternatively, NoV infections in infants could cause more serious symptoms that require hospitalisation whereas older children may not be as severely affected.

A variety of NoV genotypes (3 GI; 8 GII) were identified in this study and up to five different strains circulated during the same time period. These results are similar to studies in Brazil, Nicaragua and Tunisia where the predominance of the GII strains in hospitalised children with gastroenteritis (88-96\% of NoV positive specimens) was also noted. ${ }^{13,36,37}$ However, other studies in Brazil ${ }^{39}$ and Mexico ${ }^{40}$ found GI and GII strains at comparable frequencies. These studies were conducted over different time intervals several years ago (1998 and 1998-2005) and used different study populations. Furthermore, in years in which a new GII.4 NoV variant emerges one might expect an increase in the frequency of detection of GII strains, as observed in this study. NoV outbreaks 
are mostly associated with peaks in winter, ${ }^{41}$ whereas sporadic NoV gastroenteritis are detected continuously. ${ }^{39,42}$ In this investigation NoVs were detected year round, with a peak in November and December. GII.4 strains were detected in 9 months of the year, comprising $43 \%$ of the NoV strains. In other recent studies GII.4 strains were detected even more frequently ranging from $62.7 \%$ to $68 \% .^{13,36,37}$ This is the first report of GII.4 strains occurring in SA. Variant analysis indicated that the newly emerging GII.4 2008 variant (12/15) was most prevalent but the older 2004 variant (2/15) was also detected. The results imply that the 2008 variant is well established in the community under investigation. This study focused on a small region and more widespread NoV screening is needed to determine the true prevalence of the GII.4 2008 variant in SA.

The data suggests that $80 \%$ of the NoV infections in this study were community acquired. Nosocomial infections occurred at both hospitals, however, no outbreaks were reported and no correlation was found between community acquired cases that were admitted to hospital and the nosocomial infections. The HIV status of the patients did not significantly correlate with either acute or chronic infection or NoV genotype.

In conclusion, this study has shown that a diverse range of NoV genotypes are found in children hospitalised with gastroenteritis. The GII.4 strains dominated and the emerging GII.4 2008 variant was present in SA and probably responsible for a significant proportion of hospitalisation due to NoV infection. The high prevalence of NoVs recorded in this study highlights the necessity for a larger study and suggests that routine NoV testing should be initiated to elucidate the contribution of NoV to the burden of gastroenteritis.

\section{Conflict of interest}

None.

\section{Acknowledgements}

We thank Joukje Siebenga for providing GII.4 variant sequences. Ethical approval: Human Ethics Committee of the School of Medicine of the University of Pretoria (Protocol 138-2008).

Funding: J. Mans acknowledges a post-doctoral fellowship and research grant from the South African Poliomyelitis Research Foundation.

\section{References}

1. Ramani S, Kang G. Viruses causing childhood diarrhoea in the developing world. Curr Opin Infect Dis 2009;22(5):477-82.

2. Gray J, Desselberger U. Viruses other than rotaviruses associated with acute diarrhoeal disease. In: Zuckerman AJ, Banatvala JE, Schoub BD, Griffiths PD, Mortimer P, editors. Principles and practice of clinical virology. sixth edition ed. John Wiley \& Sons, Ltd.; 2009. p. 355-72.

3. Zheng DP, Ando T, Fankhauser RL, Beard RS, Glass RI, Monroe SS. Norovirus classification and proposed strain nomenclature. Virology 2006;346(2):312-23.

4. Green K. Caliciviridae: the noroviruses. In: Knipe DM, Howley PM, Griffin DE, Lamb RA, Martin MA, Roizman B, editors. Field's virology. fifth edition ed. Philadelphia: Lippincott Williams \& Wilkins; 2007. p. 949-79.

5. Koopmans M. Progress in understanding norovirus epidemiology. Curr Opin Infect Dis 2008;21(5):544-52.

6. Siebenga JJ, Vennema H, Zheng DP, Vinje J, Lee BE, Pang XL, et al. Norovirus illness is a global problem: emergence and spread of norovirus GII.4 variants, 2001-2007. J Infect Dis 2009;200(5):802-12.

7. Kapikian AZ, Wyatt RG, Dolin R, Thornhill TS, Kalica AR, Chanock RM. Visualization by immune electron microscopy of a $27-\mathrm{nm}$ particle associated with acute infectious nonbacterial gastroenteritis. J Virol 1972;10(5):1075-81.

8. Greig JD, Lee MB. Enteric outbreaks in long-term care facilities and recommendations for prevention: a review. Epidemiol Infect 2009;137(2):145-55.

9. Lopman BA, Reacher M, Gallimore C, Adak GK, Gray JJ, Brown DW. A summertime peak of "winter vomiting disease": surveillance of noroviruses in England and Wales 1995 to 2002. BMC Public Health 2003;3:13.

10. Lynch M, Painter J, Woodruff R, Braden C. Surveillance for foodbornedisease outbreaks-United States, 1998-2002. MMWR Surveill Summ 2006;55(10):1-42.
11. Patel MM, Hall AJ, Vinje J, Parashar UD. Noroviruses: a comprehensive review. J Clin Virol 2009;44(1):1-8.

12. Ribeiro LR, Giuberti RS, Barreira DM, Saick KW, Leite JP, Miagostovich MP, et al. Hospitalization due to norovirus and genotypes of rotavirus in pediatric patients, state of Espirito Santo. Mem Inst Oswaldo Cruz 2008;103(2): 201-6.

13. Sdiri-Loulizi K, Gharbi-Khelifi H, de Rougemont A, Chouchane S, Sakly N, Ambert-Balay $\mathrm{K}$, et al. Acute infantile gastroenteritis associated with human enteric viruses in Tunisia. J Clin Microbiol 2008;46(4):1349-55.

14. Colomba C, Saporito L, Giammanco GM, De Grazia S, Ramirez S, Arista S, et al. Norovirus and gastroenteritis in hospitalized children, Italy. Emerg Infect Dis 2007;13(9):1389-91.

15. Taylor MB, Schildhauer CI, Parker S, Grabow WO, Xi J, Estes MK, et al. Two successive outbreaks of SRSV-associated gastroenteritis in South Africa. J Med Virol 1993;41(1):18-23.

16. Wolfaardt M, Taylor MB, Grabow WO, Cubitt WD, Jiang X. Molecular characterisation of small round structured viruses associated with gastroenteritis in South Africa. J Med Virol 1995;47(4):386-91.

17. Wolfaardt M, Taylor MB, Booysen HF, Engelbrecht L, Grabow WO, Jiang X. Incidence of human calicivirus and rotavirus infection in patients with gastroenteritis in South Africa. J Med Virol 1997;51(4):290-6.

18. Taylor MB, Parker S, Grabow WO, Cubitt WD. An epidemiological investigation of Norwalk virus infection in South Africa. Epidemiol Infect 1996;116(2): 203-6.

19. Smit TK, Bos P, Peenze I, Jiang X, Estes MK, Steele AD. Seroepidemiological study of genogroup I and II calicivirus infections in South and southern Africa. J Med Virol 1999;59(2):227-31.

20. Svraka S, Duizer E, Vennema $H$, de Bruin E, van der Veer B, Dorresteijn $\mathrm{B}$, et al. Etiological role of viruses in outbreaks of acute gastroenteritis in The Netherlands from 1994 through 2005. J Clin Microbiol 2007;45(5):138994.

21. da Silva AK, Le Saux JC, Parnaudeau S, Pommepuy M, Elimelech M, Le Guyader FS. Evaluation of removal of noroviruses during wastewater treatment, using real-time reverse transcription-PCR: different behaviors of genogroups I and II. Appl Environ Microbiol 2007;73(24):7891-7.

22. Loisy F, Atmar RL, Guillon P, Le Cann P, Pommepuy M, Le Guyader FS. Realtime RT-PCR for norovirus screening in shellfish. J Virol Methods 2005;123(1): $1-7$.

23. Kageyama T, Kojima S, Shinohara M, Uchida K, Fukushi S, Hoshino FB, et al. Broadly reactive and highly sensitive assay for Norwalk-like viruses based on real-time quantitative reverse transcription-PCR. J Clin Microbiol 2003;41(4):1548-57.

24. Chan MC, Sung JJ, Lam RK, Chan PK, Lai RW, Leung WK. Sapovirus detection by quantitative real-time RT-PCR in clinical stool specimens. J Virol Methods 2006;134(1-2):146-53.

25. Kojima S, Kageyama T, Fukushi S, Hoshino FB, Shinohara M, Uchida K, et al. Genogroup-specific PCR primers for detection of Norwalk-like viruses. J Virol Methods 2002;100(1-2):107-14.

26. Messing J. New M13 vectors for cloning. Methods Enzymol 1983;101:20-78.

27. Hall TA. BioEdit: a user-friendly biological sequence alignment editor and analysis program for Windows 95/98/NT. Nucl Acids Symp Ser 1999;41:95-8.

28. Altschul SF, Madden TL, Schäffer AA, Zhang J, Zhang Z, Miller W, et al. Gapped BLAST and PSI-BLAST: a new generation of protein database search programs. Nucleic Acids Res 1997;25:3389-402.

29. Tamura K, Dudley J, Nei M, Kumar S, MEGA4:. Molecular Evolutionary Genetics Analysis (MEGA) software version 4.0. Mol Biol Evol 2007;24(8):1596-9.

30. Siebenga JJ, Vennema H, Renckens B, de Bruin E, van der Veer B, Siezen RJ, et al. Epochal evolution of GGII.4 norovirus capsid proteins from 1995 to 2006.J Virol 2007;81(18):9932-41.

31. Fabiana A, Donia D, Gabrieli R, Petrinca AR, Cenko F, Bebeci D, et al. Influence of enteric viruses on gastroenteritis in Albania: epidemiological and molecular analysis. J Med Virol 2007;79(12):1844-9.

32. Junquera CG, de Baranda CS, Mialdea OG, Serrano EB, Sanchez-Fauquier A Prevalence and clinical characteristics of norovirus gastroenteritis among hospitalized children in Spain. Pediatr Infect Dis J 2009;28(7):604-7.

33. Moyo SJ, Gro N, Kirsti V, Matee MI, Kitundu J, Maselle SY, et al. Prevalence of enteropathogenic viruses and molecular characterization of group A rotavirus among children with diarrhea in Dar es Salaam Tanzania. BMC Public Health 2007;7:359.

34. Nakagomi T, Correia JB, Nakagomi O, Montenegro FM, Cuevas LE, Cunliffe NA, et al. Norovirus infection among children with acute gastroenteritis in Recife, Brazil: disease severity is comparable to rotavirus gastroenteritis. Arch Virol 2008;153(5):957-60.

35. Onishi N, Hosoya M, Matsumoto A, Imamura T, Katayose M, Kawasaki Y, et al. Molecular epidemiology of norovirus gastroenteritis in Soma, Japan, 2001-2003. Pediatr Int 2008;50(1):65-9.

36. Bucardo F, Nordgren J, Carlsson B, Paniagua M, Lindgren PE, Espinoza F, et al. Pediatric norovirus diarrhea in Nicaragua. J Clin Microbiol 2008;46(8):257380.

37. Victoria M, Carvalho-Costa FA, Heinemann MB, Leite JP, Miagostovich M. Prevalence and molecular epidemiology of noroviruses in hospitalized children with acute gastroenteritis in Rio de Janeiro Brazil, 2004. Pediatr Infect Dis 2007;26(7):602-6.

38. Rockx B, De Wit M, Vennema H, Vinje J, De Bruin E, Van Duynhoven Y, et al. Natural history of human calicivirus infection: a prospective cohort study. Clin Infect Dis 2002;35(3):246-53. 
39. Soares CC, Santos N, Beard RS, Albuquerque MC, Maranhao AG, Rocha LN, et al. Norovirus detection and genotyping for children with gastroenteritis, Brazil. Emerg Infect Dis 2007;13(8):1244-6.

40. Long KZ, Garcia C, Santos JI, Rosado JL, Hertzmark E, Dupont HL, et al. Vitamin A supplementation has divergent effects on norovirus infections and clinical symptoms among Mexican children. J Infect Dis 2007;196(7):978-85.
41. Mounts AW, Ando T, Koopmans M, Bresee JS, Noel J, Glass RI. Cold weather seasonality of gastroenteritis associated with Norwalk-like viruses. J Infect Dis 2000;181(Suppl. 2):S284-7.

42. Lee BE, Preiksaitis JK, Chui N, Chui L, Pang XL. Genetic relatedness of noroviruses identified in sporadic gastroenteritis in children and gastroenteritis outbreaks in northern Alberta. J Med Virol 2008;80(2):330-7.

Please cite this article in press as: Mans J, et al. Emerging norovirus GII.4 2008 variant detected in hospitalised paediatric patients in South Africa. 